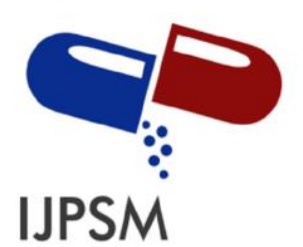

G.SAI SRUTHI et al, Int. Journal of Pharmaceutical Sciences and Medicine (IJPSM), Vol.6 Issue. 8, August- 2021, pg. 73-77

ISSN: 2519-9889

Impact Factor: 3.426

\title{
EVALUATION OF INVITRO ANTI-OXIDANT ACTIVITY OF MAGNOLIA CHAMPACA
}

\section{G.SAI SRUTHI ${ }^{*}$; K.SPANDANA; RAMANJANEYULU.K; HIMABINDHU.J Vishnu Institute of Pharmaceutical Education and Research DOI: 10.47760/ijpsm.2021.v06i08.005}

\begin{abstract}
The aim of this article is to evaluate antioxidant activity of leaf extract of Magnolia champaca by using in vitro assay. Extraction was carried out with ethanol by using Soxhlet apparatus. The invitro antioxidant activity of ethanol extract has been investigated by 1, 1-diphenyl, 2-picrylhydrazyl free radical (DPPH) method. The ethanol extract exhibited maximum antioxidant activity. The results have been compared with the standard ascorbic acid.
\end{abstract}

KEYWORDS: Antioxidant activity, DPPH, Free radicals, ethanol extract.

\section{INTRODUCTION}

Antioxidants are molecules that inhibit or quench free radical reactions and delay or inhibit cellular damage [1]. Human body has an inherent antioxidative mechanism and many of the biological functions such as the anti-mutagenic, anti-carcinogenic, and anti-aging responses originate from this Property[2,3]. Antioxidants can be categorized in multiple ways. Based on their activity, they can be categorized as enzymatic and non-enzymatic antioxidants. Enzymatic antioxidants work by breaking down and removing free radicals [4].

Antioxidant activities increase proportionally with the polyphenol content, primarily because of their redox properties [5]. In addition to plant extracts, numerous naturally occurring compounds are useful as antioxidants, ranging from $\alpha$-tocopherol and $\beta$-carotene to plant antioxidants such as phenolic compounds, alkaloids, and organic sulfur compounds [6].

Magnolia champaca grows to 50 metres $(160 \mathrm{ft})$ or taller. Its trunk can be up to 1.9 metres $(6.2 \mathrm{ft})$ in diameter. The tree has a narrow umbelliform. It has strongly fragrant flowers in 


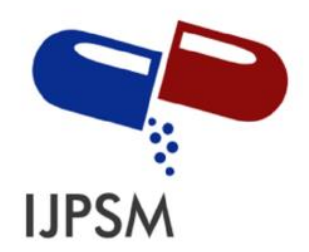

G.SAI SRUTHI et al, Int. Journal of Pharmaceutical Sciences and Medicine (IJPSM), Vol.6 Issue. 8, August- 2021, pg. 73-77

ISSN: 2519-9889

Impact Factor: 3.426

varying shades of cream to yellow-orange, during June to September.[7]. Magnolia champaca however is more rare and has a strong perfume, and is not that commonly or plentifully used for example in hair it is worn singly or as a small corsage but rarely as a whole garland, and for bridal beds it is most often jasmine and roses while for bowls of water to be placed around rooms usually other, more colourful for visual decoration and less strongly perfumed flowers are used.[8]

PLANT COLLECTION AND AUTHENTICATION The leaves of the plant Magnolia champaca were collected in the month of March in Narsapur, Medak District, Telangana, India. The plant was authenticated by M.Malla Reddy (M.Sc, M.Phil in Botany), Retired lecturer in Botany, Vikarabad, Telangana.

\section{MATERIAL USED}

In the present study1,1diphenyl, 2-picryl-hydrazyl free radical (DPPH) and alcohol used during investigation of antioxidant activity. All the material was used in laboratory grade.

\section{PREPARATION OF PLANT EXTRACT}

The leaves of Magnolia champaca were shade dried and crushed into powder and sieved to get a coarse powder. The powder was subjected to soxhlet extraction using ethanol for 72 hours. The solvent was evaporated using rotary evaporator then the extract was used for the evaluation of antioxidant activity.

\section{ANTIOXIDANT ACTIVITY}

\section{DPPH Scavenging activity:}

The molecule 1,1-diphenyl-2-picrylhydrazyl (a,a-diphenyl-b-picrylhydrazyl;DPPH) is characterized as a stable free radical by virtue of the delocalisation of the spare electron over the molecule as a whole, so that the molecule does not dimerize, as would be the case with most other free radicals. The delocalization of electron also gives rise to the deep violet color, characterized by an absorption band in ethanol solution centered at about $517 \mathrm{~nm}$. When a solution of DPPH is mixed with that of a substrate (AH) that can donate a hydrogen atom, then this gives rise to the reduced form with the loss of this violet color. 


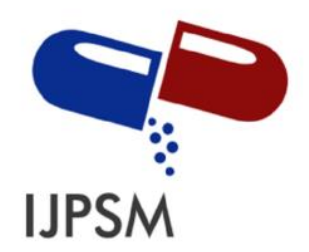

G.SAI SRUTHI et al, Int. Journal of Pharmaceutical Sciences and Medicine (IJPSM), Vol.6 Issue. 8, August- 2021, pg. 73-77

ISSN: 2519-9889

Impact Factor: 3.426

\section{Procedure:}

The free radical scavenging activity of all the samples was evaluated by 1, 1-diphenyl-2picryl-hydrazyl (DPPH) according to the previously reported method by Shen et al., 2010. Briefly, a $0.1 \mathrm{mM}$ solution of DPPH in ethanol was prepared and $1 \mathrm{~mL}$ of this solution was added to $3 \mathrm{ml}$ of the solution of all samples in ethanol at different concentration $(1,2,3,4,5$ \&10 $\mu \mathrm{g} / \mathrm{mL}$ ). The mixtures were shaken vigorously and allowed to stand at room temperature for 30 minutes. Then the absorbance was measured at $517 \mathrm{~nm}$ using a UV-VIS spectrophotometer. Ascorbic acid was used as the reference. Lower absorbance values of reaction mixture indicate higher free radical scavenging activity. The capability of scavenging the DPPH radical was calculated by using the following formula.

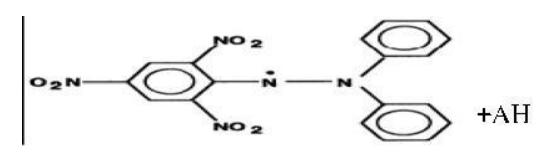

DPPH scavenging effect $(\%$ inhibition $\left.)=\{(\mathrm{A} 0-\mathrm{A} 1) / \mathrm{A} 0)^{*} 100\right\}$

Where,

$\mathrm{A} 0$ is the absorbance of the control reaction

A1 is the absorbance in presence of all of the extract samples and reference.

All the tests were performed in triplicates and the results were averaged(9).

Determination of $\mathrm{IC}_{50}$ :

The $\mathrm{IC}_{50}$ value (The concentration of sample required to scavenge $50 \%$ of DPPH free radicals) was determined by interpolation from the calibration curve plotted between percentage inhibition and sample concentration and expressed as microgram per ml. 


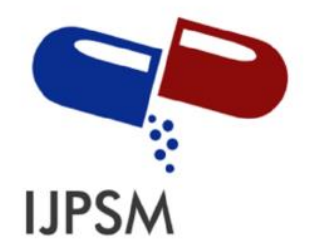

G.SAI SRUTHI et al, Int. Journal of Pharmaceutical Sciences and Medicine (IJPSM), Vol.6 Issue. 8, August- 2021, pg. 73-77

ISSN: 2519-9889

Impact Factor: 3.426

\section{RESULTS AND DISCUSSION}

Antiradical activity assay is based on the reduction of 1, 1-diphenyl-2-picrylhydrazyl (DPPH). Due to the presence of an odd electron it gives a strong absorption maximum at $517 \mathrm{~nm}$. As this electron becomes paired off in the presence of a hydrogen donor, i.e. a free radical scavenging antioxidant, the absorption strength is decreased, and the resulting decolorization is stoichiometric with respect to the number of electrons captured. The decomposition of DPPH free radicals by Magnolia champaca may at least partly result from its antioxidant and free radical scavenging activity.

Table 2: DPPH free radical scavenging activity

\begin{tabular}{|c|c|c|}
\hline Concentration $\mu \mathrm{g} / \mathrm{ml}$ & $\begin{array}{c}\text { Standard } \\
\text { Percent scavenging }(\%)\end{array}$ & $\begin{array}{c}\text { Ethanol extract } \\
\text { Percent scavenging (\%) }\end{array}$ \\
\hline 20 & 92 & 93 \\
\hline 40 & 93 & 95 \\
\hline 60 & 94 & 97 \\
\hline 80 & 96 & 98 \\
\hline 100 & 97 & 99 \\
\hline
\end{tabular}

\section{CONCLUSION}

The results obtained in the present study indicate that Magnolia champaca ethanolic extract exhibit significant free radical scavenging and antioxidant activity. The overall antioxidant activity might be attributed to its phytochemical constituents. The findings of the present study suggest that, this Magnolia champaca could be a potential source of natural antioxidant that could have great importance as therapeutic agent in preventing or slowing the progress of aging and age associated oxidative stress related degenerative diseases. 


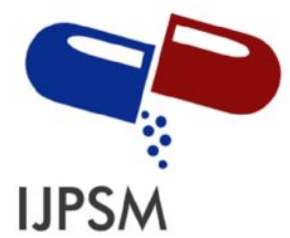

G.SAI SRUTHI et al, Int. Journal of Pharmaceutical Sciences and Medicine (IJPSM), Vol.6 Issue. 8, August- 2021, pg. 73-77

ISSN: 2519-9889

Impact Factor: 3.426

ACKNOWLEDGEMENT The authors sincerely thankful to our chairman Shri.K. V. Vishnu Raju Garu and our college Vishnu Institute of Pharmaceutical Education and Research Principal Dr. Ramesh Alluri and staff members for towards our project.

\section{REFERENCES}

[1]. I. S. Young and J. V. Woodside, J. Clin. Pathol., 2001, 54, 176-186.

[2]. Gulcin I. Antioxidant activity of food constituents: an overview. Arch Toxicol. 2012;86:345-391. doi: 10.1007/s00204-011-0774-2. ]

[3]. Gocer H, Gulcin I. Caffeic acid phenethyl ester (CAPE): correlation of structure and antioxidant properties. Int J Food SciNutr. 2011;62:821-825. doi: 10.3109/09637486.2011.585963.

[4]. S.A. Tasaduq, K. Singh, S. Sethi, S.C. Sharma, K.L. Bedi, J.Singh, B.S. Jaggi, R.K. Johri, Hepatocurative and antioxidant profile of HP-1, a polyherbalphytomedicine Hum. Exp. Toxicol., 22 (2003), pp. 639645.

[5]. S.A. Mohamed, F.A. Marzouk, M.A. Moharram, A.M. Mohamed, E.A. Gamal-Eldeen, Anti-cancer and antioxidant tannins from Pimentadioica leaves Z Natur Forsch, 62 (2006), pp. 526-536.

[6]. efloras.org: Flora of China treatment of Michelia (Magnolia) champaca . accessed 7.12.2015.

[7]. Minter, S. "Fragrant Plants." in Prance, G. and M. Nesbitt. (2005). The Cultural History of Plants. London: Routledge. 242.

[8]. Shen Q, Zhang B, Xu R, Wang Y, Ding X, Li P. Antioxidant activity in vitro of selenium-contained protein from the se-enriched. Bifodobacterium animalis 01. Anaerobe, 2010; 16: 380-386. 